\title{
The Relationship Between Stress Coping Styles and Sense of Humor Styles Among Teenagers
}

\author{
Narges Mirani Sargazi ${ }^{1, ~ *}$, Afsaneh Pudineh ${ }^{2}$, Reza Mirzaei Rad $^{3,}$,, Mohadeseh Ordoni² \\ ${ }^{1}$ Department of Educational Management, Shiraz University, Shiraz, Iran \\ ${ }^{2}$ Educational Psychology, Sistan and Baluchestan University, Zahedan, Iran \\ ${ }^{3}$ Islamic Azad University, Pomegranate Anar, Iran
}

Email address:

nargesmiranisargazi@gmail.com (N. M. Sergzi),R.mirzaei@gmail.com (R. M. Rad)

${ }^{*}$ Corresponding author

\section{To cite this article:}

Narges Mirani Sargazi, Afsaneh Pudineh, Reza Mirzaei Rad, Mohadeseh Ordoni. The Relationship Between Stress Coping Styles and Sense of Humor Styles Among Teenagers. American Journal of Applied Psychology. Vol. 9, No. 1, 2021, pp. 9-15.

doi: 10.11648/j.ajhr.20210901.12

Received: December 9, 2020; Accepted: December 25, 2020; Published: February 23, 2021

\begin{abstract}
Healthy jokes are one of the best ways to cope with life's pressures. The humor is relieved or prevented by accepting the fleeting self-esteem of a hidden desire, which creates pleasure or happiness, while at the same time alleviating the anguish that often manifests the miracle of a wish. Sudden release of tension, pleasant surprise Bring it. However, the unconscious root of one's stress changes somehow in a joke, which is often not uncomfortable. The research method was descriptive-survey. The statistical population of this study included all teenage girls and boys of Zahedan in the academic year of 2019 and the sample was selected by random sampling method \&using Cochran formula which was 270 people. The standardized questionnaires used for data collection included Andrews \& Parker Stress Coping Strategies Questionnaire (1990) and Humorous Styles Questionnaire of Martin et al. (1988). Spss25 software was used for data analysis. In this study, the demographic status of the subjects was examined by age and gender. According to the descriptive statistics, among the dimensions of stress coping styles, the highest mean was related to problem-oriented style and among the dimensions of humor styles, the highest mean was related to self-destructive style. The results of the data analysis confirmed all the existing hypotheses and showed that there is a relationship between coping styles and humor styles in Teenagers.
\end{abstract}

Keywords: Stress Coping Styles, Humorous Styles, Suicidal, Bonding, Aggressive

\section{Introduction}

The world we live in is full of fears and worries with all its wonders, beauties, and advances. Stress is inevitable and all humans have experienced it. Stress is a vague and complex term that many scholars have termed it a difficult and difficult term Although the term is familiar and familiar, stress has many definitions [1]. Defines stress as a set of nonspecific reactions of the organism to any kind of adaptation demand. In other words, stress is the result of the interaction between the individual and the environment and causes heterogeneity, whether real or unrealistic, between the requirements of one's situation and one's biological, psychological, and social resources [2, 3]. As mentioned, adolescence is a transition from childhood to adulthood, and transition from one transition to another is usually accompanied by stress. As some studies have reported, parents' concern about children at an early age is very high and may be subject to a great deal of stress [4]. Some psychologists have described this period as a period of chaos and stress, believing that if adolescents go through this course they will become healthy adults and play their part well, but if there are difficulties in doing so, and there are problems with adolescent mental health that deviate from the mainstream and go astray [1]. Carnick, Edelman, Engebreston, and Espens $[5,6]$ stated that the stress syndrome is a person's response to events or changes that conflict with his or her social status. These reactions result in one or more cognitive, behavioral, emotional, and physical reactions that occur immediately or delayed. Some of these responses include sleep disturbances, hypertension, 
depression and anxiety. Adolescents face a variety of stressful situations ranging from everyday life issues to major life events. When discussing stress and how to deal with it in adolescents, one must consider the social environment, including the family environment $[6,7]$.

Theorists believe that whenever humans attribute negative events to causes in their self that are stable and affecting their multiple lives, the likelihood of slowness in response to negative life events is greater than There will be others. Abramson and his colleagues argue that one has the same ways of attributing events to one's life, which they call attribution practices. The same practices determine the amount of stressful events, the reactions of helplessness and the slow response to difficult events. Various studies have shown that pessimistic attitudes by directly decreasing immune system performance and indirectly by reducing circadian health behavior make one more susceptible to physical illnesses [8].

In the face of stress, people try to adapt to an undesirable situation by employing coping styles. Usually people react by pressing against the situation to bring it back into balance. This reaction is important because it directly affects one's future abilities. Some reactions are adaptive because they lead to greater balance and lower stress. And some other reactions are incompatible because they create more secondary problems that have a negative impact on one's future status (such as addiction). Adverse reactions (which are long-term effects of ineffective coping strategies) include responses such as avoiding anxious situations, aggression, excessive drug use, physical difficulty, and accepting the patient's role and substance dependency [9], Effective coping strategies reduce one's response to high levels of stress and modify its harmful effects [10].

Therefore, in recent years, attention has been paid to the sources of stress and coping styles and it has been shown that effective coping styles play an important role in stress reduction [11]. Stress and coping strategies are among the first topics to be studied empirically in the last five decades. It is arguable that underlying a significant percentage of physical and mental distress, endurance, and disability are Coping with it. Research has shown that when people are poor at managing an organization after paying attention to their well-being and establishing friendly relationships with it, a higher percentage of people suffer from stress and negative emotions [12]. In the face of stress, people try to adapt to an undesirable situation by employing coping styles. Coping styles have a variety of different definitions. Andler and Parker [13] proposed three types of stress coping styles: 1 . Problem-centered coping styles 2. Emotion-focused 3. Avoidance style. People who are not able to cope effectively are more likely to experience stress and the resulting inadequacy can lead to mental disorders. The main cause of many psychological problems are inappropriate coping styles. Research has shown that if adolescents are not equipped with stress coping styles and have low ability to cope with their own and others' emotions, they will be less able to deal with adolescent crises and exhibit behavioral problems such as aggression, depression, and anxiety [14].
Humorous situations in stressful situations broaden one's perspective towards solving problems more effectively and being more adaptable to the environment and pressures. Jokes in stressful situations increase feelings of self-esteem, self-esteem, and self-esteem $[15,16]$. Laughter and humor are basically one of the ways to communicate with others and have miraculous effects on relationships and performance improvement, for many years we have heard that humor and laughter are beneficial to health. There has been a lot of research on humor. The findings of most studies suggest that healthy jokes are one of the best ways to cope with life stress. Laughter enhances cardiovascular activity, regulates brain waves, corrects the valves of the heart, and reduces pain perception. The joke that comes from healthy motives helps the leakage of happy hormones lower the patient's happiness and relaxation related to stress and boost the body's immune system. Therefore, even in the most serious and fatal diseases, he can spend most of his life. Positive effects of joke can be emphasized on various aspects such as use as emotional stimuli, attentive behavior, social distance reduction, and management tools [17] Individuals with a deep sense of humor after negative life events are likely to exhibit a better mood [18]. In McGee's conceptual model [19], a joke causes the person to consider the positive side of events, and this makes them able to see the events in a non-magical and funny way, thus reducing the amount of stress and anxiety in situations. The challenge is diminished [20].

Much research has been done on these variables, but no research has investigated the relationship between these two variables. The study of victim, Hosseini and Divine [21] showed that there is a positive relationship between humor and problem-oriented coping style, and there is a negative relationship between humor and avoidant and emotion-focused coping styles. The results of Kamaliaigli and Hassani's [22], research showed that students who use emotion-focused and avoidant coping styles are more stressful than the problemfocused group and face stressful situations rather than confrontation and management. Their emotions are more likely to drown in stressful conditions, thus indicating a readiness to wear out in a mass of emotions. The results of the study by Por shariffi et al [23] showed that happiness was negatively associated with depression, stress and suicidal ideation and was positively associated with social support.

According to this content, Teenagers is a time of severe crisis and has many challenges. It therefore requires special care in the social and family environment. If you can identify the components of wit and stress coping styles in adolescents, one can hope that their mental health will be improved in a positive way, that you will easily pass the teenage crisis and balance your life as much as possible. Takes. The purpose of this study was to investigate whether there is a relationship between coping styles and humor styles among adolescents.

\section{Research Methodology}

The present study is of practical purpose and is one of the descriptive-survey studies that is based on determining the 
relationship between variables. Since the present study seeks to investigate the relationship between coping styles, humor styles and attitude toward suicide in adolescents, it is descriptive and correlational in nature. Survey method was used for data collection and since the results of the research can be a guide for counseling and psychotherapy centers of education institutes, welfare organization, education organization, so it is among the applied research target.

The statistical population of this study is all Teenagers aged 15-17 years in Zahedan (both boys and girls) in 2018-2019. In order to calculate the desired sample size and according to previous studies the population variance estimate was 0.25 so in this study suitable sample for research using Cochran formula with a confidence level of 0.95 and accuracy of 0.05 sample size was determined. First, by using cluster random sampling method, 3 districts of Zahedan District 1 and 9 districts of District 1 were selected. Based on the above calculations, the sample of the study consisted of 270 students of 10th, 11th and 12th grade Teenagers male and female students. Areas (Experimental, Mathematics, Humanities) engaged in an education area of Zahedan in the academic year 2018-2019 The study. The sample consisted of 270 secondary school students, of whom 144 were girls and 126 were boys, 89 were 15, 98 were 16, and 83 were 17. By the age of 10th, 11th and 12th grade, students are about 15-17 years old and cover almost the early to late teens.

Since the most common tool used in the descriptive-survey research is questionnaire and interview, in this study, the data collection tool of the selected sample is the questionnaire.

A) Endler \& Parker Questionnaire [13]: This questionnaire has been translated by Akbarzadeh (1997). The test consists of 48 items whose responses are based on a 5-point Likert scale (never (1) to always (5)). The three main areas of coping behaviors include problem-focused coping, emotion-focused coping, and problem avoidance or avoidance. Pearson correlation coefficient was used to calculate the correlation between the factors of Coping Stress Questionnaire. Problemcentered $=0.58$ and Emotion-focused $=0.55$ and Avoidance $=$ 0.93 (Hajat Beigi, 2000). Cronbach's alpha was used to obtain the reliability of the Stress Coping Style Questionnaire.

Table 1. Reliability of Stress Coping Inventory Questionnaire Components.

\begin{tabular}{ll}
\hline Component & Reliability \\
\hline Problem-oriented & $0 / 93$ \\
Emotion-focused & $0 / 88$ \\
Avoidance & $0 / 94$ \\
\hline
\end{tabular}

B) Martin et al. (1988) standard humor questionnaire: standard humor questionnaire: The wit styles questionnaire was designed by Martin et al [25] This questionnaire has 32 items and 4 factors. Each item on the five-part Likert scale ranged from very low (score 1) to very high (score 5). Reliability or validity has to do with the extent to which a tool is used to measure what we think it is [24]. In the present study, the reliability of the questionnaire was determined by Cronbach's alpha method as follows:
Table 2. Reliability of Components of the Humor Style Questionnaire.

\begin{tabular}{ll}
\hline Component & Reliability \\
\hline Attachment style & $0 / 88$ \\
Self-increasing style & $0 / 93$ \\
Aggressive style & $0 / 83$ \\
Self-defeating style & $0 / 90$ \\
\hline
\end{tabular}

After collecting the questionnaires, the data were analyzed using Spss 25 software. The data is first coded and then entered into the software. They are then analyzed using descriptive and inferential statistics. In descriptive statistics section, frequency distribution tables, percentages, mean and variance were used, and inferential statistics, Pearson correlation coefficient and multiple regression analysis were used.

\section{Findings}

The purpose of this study was to investigate the relationship between coping styles and humor styles among adolescents in Zahedan in the academic year 2018-2019. The results showed that $53.3 \%$ of the sample were boys and $46.7 \%$ were girls. Therefore, it can be said that the majority of the sample was boys and the highest percentage of the sample was 16 years old. And the youngest were 17 years old.

Descriptive findings of Stress Coping Inventory

Table 3. Descriptive Statistics for Stress Coping Styles.

\begin{tabular}{lll}
\hline Variable & Mean & Standard deviation \\
\hline Problem-oriented style & $45 / 71$ & $10 / 33$ \\
Circuit thriller style & $44 / 98$ & $11 / 18$ \\
Avoidance style & $31 / 84$ & $11 / 71$ \\
\hline
\end{tabular}

According to Table 3, examining the means of stress coping styles shows that among the dimensions of stress coping styles, the highest average is related to problemoriented style and the lowest average is to avoidant style.

Descriptive findings of the wit styles questionnaire

Table 4. Descriptive statistics related to humor styles and their dimensions.

\begin{tabular}{lll}
\hline Variable & Mean & Standard deviation \\
\hline Total score & $93 / 66$ & $7 / 04$ \\
Bonding & $20 / 19$ & $5 / 39$ \\
Self-increasing & $20 / 54$ & $6 / 68$ \\
Aggressive & $18 / 86$ & $6 / 40$ \\
Self-defeating & $34 / 10$ & $10 / 70$ \\
\hline
\end{tabular}

According to Table 4, the study of the mean of wit styles shows that among the wit styles, the highest mean is related to suicidal style and the lowest mean is to aggressive style. According to the data obtained from the research, by using Bartlett sample volume adequacy test, sample size adequacy test was investigated and then by Pearson correlation test and multiple linear regression tests the research hypotheses were tested.

\subsection{Sample Size Adequacy Test}

According to Table 5, it is observed that since the value of $\mathrm{x} 2$ calculated from the critical value of table with degree of 
freedom 5995 is significant at $\mathrm{p} \leq 0.05$ level, then the results show that sample size is sufficient. Pearson correlation coefficient and multiple regression were used to investigate the relationship between the variables.
Table 5. Bartlett test for sample volume adequacy.

\begin{tabular}{llll}
\hline Significance level & Degrees of freedom & K2 & KMO \\
\hline $0 / 000$ & 5995 & $21845 / 104$ & $0 / 864$ \\
\hline
\end{tabular}

\subsection{Correlation Coefficient Test}

Table 6. The correlation matrix between the research variables.

\begin{tabular}{|c|c|c|c|c|c|c|c|c|c|c|c|c|}
\hline Variable & 1 & 2 & 3 & 4 & 5 & 6 & 7 & 8 & 9 & 10 & 11 & 12 \\
\hline Problem-based style & $-0 / 062$ & $0 / 154^{*}$ & $-0 / 102$ & $-0 / 153^{*}$ & $-0 / 009$ & 1 & & & & & & \\
\hline Circuit thriller style & $-0 / 099$ & $0 / 190^{* *}$ & $-0 / 164^{* *}$ & $-0 / 150^{*}$ & $0 / 055$ & $0 / 736^{* *}$ & 1 & & & & & \\
\hline Avoidance style & $0 / 541^{* *}$ & $-0 / 625^{* *}$ & $0 / 587^{* *}$ & $0 / 449^{* *}$ & $-0 / 500^{* *}$ & $-0 / 072$ & $-0 / 101$ & 1 & & & & \\
\hline Self-increasing style & $-0 / 237^{* *}$ & $0 / 355^{* *}$ & $-0 / 269^{* *}$ & $-0 / 304^{* *}$ & $0 / 235^{* *}$ & $0 / 265^{* *}$ & $0 / 297^{* *}$ & $-0 / 309^{* *}$ & $0 / 889^{* *}$ & 1 & & \\
\hline Aggressive style & $0 / 255^{* *}$ & $-0 / 286^{* *}$ & $0 / 188^{* *}$ & $0 / 279^{* *}$ & $-0 / 191^{* *}$ & $-0 / 291^{* *}$ & $-0 / 274^{* *}$ & $0 / 216^{* *}$ & $-0 / 849^{* *}$ & $-0 / 804^{* *}$ & 1 & \\
\hline Self-defeating style & $0 / 274^{* *}$ & $-0 / 337^{* *}$ & $0 / 244^{* *}$ & $0 / 299^{* *}$ & $-0 / 252^{* *}$ & $-0 / 277^{* *}$ & $-0 / 287^{* *}$ & $0 / 265^{* *}$ & $-0 / 843^{* *}$ & $-0 / 917^{* *}$ & $0 / 835^{* *}$ & 1 \\
\hline
\end{tabular}

** Significance at the 0.01 level

*Significance at the 0.05 level

- Bold coefficients and no * are not significant

\subsection{Correlation Coefficient Test}

Table 7. The correlation coefficient between stress coping styles and wit styles.

\begin{tabular}{|c|c|c|c|c|c|}
\hline The correlation matrix & & Bonding style & Self-increasing style & Aggressive style & Self-defeating style \\
\hline \multirow{3}{*}{$\begin{array}{l}\text { Problem-oriented Coping } \\
\text { Style } \\
\text { Emotion-focused coping } \\
\text { style }\end{array}$} & Pearson correlation coefficient & $0 / 268$ & $0 / 265$ & $-0 / 291$ & $-0 / 277$ \\
\hline & Significance level & $0 / 000$ & $0 / 000$ & $0 / 000$ & $0 / 000$ \\
\hline & Pearson correlation coefficient & $0 / 261$ & $0 / 297$ & $-0 / 274$ & $-0 / 287$ \\
\hline \multirow{2}{*}{ Avoidant coping style } & Pearson correlation coefficient & $-0 / 262$ & $-0 / 309$ & $0 / 216$ & $0 / 265$ \\
\hline & Significance level & $0 / 000$ & $0 / 000$ & $0 / 000$ & $0 / 000$ \\
\hline
\end{tabular}

According to Table 7, the results of correlation coefficient test show that among stress coping styles, problem-oriented and emotion-focused styles have significant and direct relationship with attachment and self-enhancing styles of humor ( $\mathrm{P} \geq 0.05)$; Aggressive and suicidal humor have inverse and significant relationship $(\mathrm{P} \geq 0.05)$. In addition, the findings also indicate that other stress coping styles, namely avoidance style, have inverse and significant relationship with attachment and self-increasing humor styles (05). But it has a direct and significant relationship with aggressive and suicidal styles $(\mathrm{P} \geq 0.05)$. It can be said that people with a connective and addictive sense of humor usually act when confronted with stress, problem-solving and emotion-focused, and people with aggressive and self-destructive humor style act more avoidant when confronted with stress.

Multiple regression was used to investigate the predictability of humor styles based on stress coping styles. As such, humor styles are considered to be the criterion variables that influence the predictor variables of stress coping styles.

Table 8. Summary of Multiple Regression Coefficients of Humor Styles Based on Stress Coping Styles.

\begin{tabular}{|c|c|c|c|c|c|c|c|c|c|}
\hline Criterion variable & Predictive variable & $\beta$ & Beta & $t$ & P-value & $\boldsymbol{R}$ & $\overline{R^{2}}$ & $F$ & P-value \\
\hline \multirow{4}{*}{ Bonding style } & Fixed & $3 / 163$ & & $6 / 849$ & $0 / 000$ & \multirow{4}{*}{$0 / 371$} & \multirow{4}{*}{$0 / 137$} & \multirow{4}{*}{$14 / 116$} & \multirow{4}{*}{$0 / 000$} \\
\hline & Problem-based style & $0 / 261$ & $0 / 167$ & $1 / 987$ & $0 / 048$ & & & & \\
\hline & Circuit thriller style & $0 / 229$ & $0 / 114$ & $1 / 357$ & $0 / 176$ & & & & \\
\hline & Avoidance style & $-0 / 367$ & $-0 / 239$ & $-4 / 171$ & $0 / 000$ & & & & \\
\hline \multirow{3}{*}{ Self-increasing style } & Fixed & $3 / 242$ & & $7 / 234$ & $0 / 000$ & \multirow{3}{*}{$0 / 414$} & \multirow{3}{*}{$0 / 172$} & \multirow{3}{*}{$18 / 385$} & \multirow{3}{*}{$0 / 000$} \\
\hline & Problem-based style & $0 / 159$ & $0 / 103$ & $1 / 247$ & $0 / 213$ & & & & \\
\hline & Avoidance style & $0 / 428$ & $-0 / 282$ & $-5 / 022$ & $0 / 000$ & & & & \\
\hline \multirow{4}{*}{ Aggressive style } & Fixed & $5 / 366$ & & $13 / 588$ & $0 / 000$ & \multirow{4}{*}{$0 / 359$} & \multirow{4}{*}{$0 / 129$} & \multirow{4}{*}{$13 / 084$} & \multirow{4}{*}{$0 / 000$} \\
\hline & Problem-based style & $-0 / 261$ & $-0 / 196$ & $-2 / 325$ & $0 / 021$ & & & & \\
\hline & Circuit thriller style & $-0 / 188$ & $-0 / 110$ & $-1 / 304$ & $0 / 193$ & & & & \\
\hline & Avoidance style & $0 / 249$ & $-0 / 191$ & $3 / 312$ & $0 / 001$ & & & & \\
\hline \multirow{3}{*}{ Self-defeating style } & Fixed & $5 / 051$ & & $12 / 383$ & $0 / 000$ & \multirow{3}{*}{$0 / 385$} & \multirow{3}{*}{$0 / 148$} & \multirow{3}{*}{$15 / 418$} & \multirow{3}{*}{$0 / 000$} \\
\hline & Problem-based style & $-0 / 202$ & $0 / 145$ & $-1 / 742$ & $0 / 083$ & & & & \\
\hline & Avoidance style & $0 / 325$ & $0 / 238$ & $4 / 190$ & $0 / 000$ & & & & \\
\hline
\end{tabular}


According to the results of Table 8 , it can be said that stress-avoidance and problem-avoidance styles can predict attachment and aggressive styles. However, the results suggest that emotion-focused style is not recognized as a predictor of attachment and aggressive style. The results also show that both emotion-oriented and avoidant styles are able to predict self-increasing style but problem-solving style is not predictive of self-increasing style. In addition, examining the significance levels and the corresponding t-statistic indicate that only the avoidant style can predict selfdestructive style among stress coping styles. Results of multiple regression analysis showed that stress coping styles interact with regression coefficients of $0.37,0.41,0.36$ and 0.39 , respectively, about $14 \%$ of the attachment style variance, $17 \%$ of the self-additive style variance. Predict $13 \%$ of the variance in aggressive style and $15 \%$ of variance in suicidal style. It should be noted that according to the beta coefficients and the corresponding t-statistic, the relationship of the linker style with the direct orbit problematic style and with the inverse avoidance style; And with direct shunting style; and the relation of suicidal style to direct shunting.

\section{Discussion}

The aim of this study was to investigate coping styles and wit styles in adolescents. The first finding showed that there is a direct and significant relationship between stress coping styles, problem-oriented and emotion-focused styles with attachment and self-enhancing styles of humor, and inverse and significant relationship with aggressive and suicidal humor styles. have. In addition, the findings suggest that the other styles of coping with stress, namely avoidance, are inversely related to attachment and self-enhancing styles of humor, but have a direct and significant relationship with aggressive and suicidal styles. Explaining the above findings, it can be said that people with attachment and self-enhancing humor style usually act in stress, problem-focused and emotion-focused ways, and individuals with aggressive and self-destructive humor style when confronted with stress more Avoid acting. The results of this section of the present study are consistent with those of Ghorbani et al. [21] and Poursharifi et al. (2012). It can be said that much research has been done on humor; the findings of most studies suggest that healthy humor is one of the best ways to cope with life's pressures [15].

Research suggests that adapted humor is positively correlated with a variety of psychological problems, but undated humor is associated with mental health. The joke is a universal, positive activity that people from different social and cultural contexts experience throughout the world and refer to a quality of action, speech and writing that makes it fun and entertaining. In addition to humor, a coping strategy, considered as a mechanism for anxiety and as a way of coping with life's problems, is actually a survival skill to get away from a problem [26]. The coping process is mainly one of the activities, cognitive and behavioral actions of the individual to manage stress. Stone et al. consider coping as a conscious effort to cope with stressful demands. This coping reduces the behavioral responses learned by limiting the importance of dangerous or unpleasant stress situations [2].

Other findings showed that among stress coping styles, both problem-oriented and avoidant styles were able to predict attachment and aggressive styles. However, the results suggest that emotion-focused style is not recognized as a predictor of attachment and aggressive style. The results also show that both emotion-oriented and avoidant styles are able to predict self-increasing style but problem-solving style is not predictive of self-increasing style. In addition, examining the significance levels and the corresponding tstatistic indicate that only the avoidant style can predict selfdestructive style among stress coping styles. It should be noted that according to the beta coefficients and the corresponding t-statistic, the relationship of the linker style with the direct orbit problematic style and with the inverse avoidance style; And with direct shunting style; and the relation of suicidal style to direct shunting. The results of this study are in line with those of Poursharifi et al. and Ghorbani et al. [21, 23]. In explaining the above findings, it can be stated that in the emotion-focused style of the individual to modulate the stressor and achieve the goal, it regulates the emotional states associated with or caused by the stressor. This style of practice affects one's attitude toward the stressor and their evaluation and interpretation of it [2]. Explaining the above findings, it can be said that studies show that if adolescents are not equipped with effective coping strategies and have little ability to comprehend their own and others' emotions, they will deal with stress and crisis. Adolescents are less likely to be aggressive and have more behavioral problems such as aggression, depression, and anxiety [14].

Applying inappropriate strategies to deal with stressors can increase problems, while appropriate coping strategies can have beneficial consequences [27]. Humor is a tool for feeling physical and mental. A strong sense of humor reduces symptoms of anxiety and depression and increases social functioning. Also, one who has a sense of humor shows a higher level of daily functioning, social functions, and emotion. The higher the level of humor, the negative aspects of mental health decrease and social functioning increases [28]. Laughter is a kind of way out of the grip of emotional distress. Freud recognized the intruder by accepting the fleeting self-protection of a hidden or forbidden desire that creates pleasure or happiness, while at the same time alleviating the anguish that often manifests the miracle of a desire and forbidding it by forbidding it. And by ridiculing it as a joke or cartoon it releases the inner tension. The sudden release of tension gives a great surprise. Whereas the unconscious root of one's stress changes somehow in a joke that is often not uncomfortable [29].

\section{Conclusion}

Overall, the findings of the present study showed that people with attachment and self-enhancing humor style 
usually act in stress, problem-focused, and emotion-focused ways, and individuals with aggressive and self-destructive humor style deal more with stress. Avoid acting. Among stress coping styles, problem-oriented and emotion-focused styles have a significant and direct relationship with attachment and self-enhancing styles of humor, and avoidance style has a significant and inverse relationship with attachment and self-enhancing styles of humor, but It has a direct and significant relationship with aggressive and suicidal styles. Due to the development of machine life and increasing psychological pressure on people, it is necessary to provide solutions that keep people's mental health at the desired level and overcome the problems and obstacles of people's adaptation to the environment.

Therefore, humor is presented as one of those strategies to increase mental health and overcome problems and obstacles that in themselves lack any credibility and value. Therefore, it is recommended that training skills to overcome stress and increase Students' humor should be one of the main programs of education. it is recommended that adequate training be provided to increase the use of stress coping styles and positive humor styles to reduce stress and increase happiness in adolescents because prevention is better than treatment. It also seeks to push adolescents away from self-destructive and aggressive styles, thereby increasing their coping ability and increasing their self-awareness, thus controlling their emotions properly. The direct relationship between attachment style with problem-oriented style and selfadditive style with emotion-focused style leads to the reduction of emotional distress and the severity of cognitive stressfulness severity, thus reducing suicide attitudes. So consider cultivating and paying attention to these relationships first. Programs can also be set up to raise people's awareness to improve their mental health by educating them on how to deal with stress and choosing the right style when faced with stress, by enhancing their sense of humor in Teenagers.

The present study also had some limitations, such as: The physically and psychologically changing status of some adolescent motivated to commit suicide may affect their response to questionnaires and the lack of similar research regarding research title and scientific resource limitation. Research on variables has made it difficult to collect library information.

\section{References}

[1] Ganji, Hamza, (2009), Mental Health, tenth edition. Tehran: Arasbaran.

[2] Cheraghi, Monvar, (2015), The Relationship between Parenting Styles, Emotional Intelligence, and Coping Styles with High School Students, MSc Thesis, Marvdasht Azad University.

[3] Sunil, K., (2009). Role of emotional intelligence in managing stress and anxiety at work place. ASBBS Annual conference: Las vegas, American.
[4] Weymouth, B. B. (2013). Parent-adolescent Hostility: A Family Systems Approach (Doctoral dissertation, University of North Carolina at Greensboro).

[5] Carnick, J.; Edelman, R. J.; Engebreston, T. o; \& Espnes, G. A. (1983). Woman, Anger and Cardiovasular Responses to stress. Journal of Psychosomatic Research. 39 (3), 251-259.

[6] Mirzaei, Ghodratollah, (2014), The Effectiveness of the Integrated Approach to Emotional Intelligence Training and Creative Thinking on Test Anxiety and Coping Stress in Male Students of Shiraz, M. Sc., Islamic Azad University, Marvdasht Branch.

[7] Compas, B. E. (1987). Coping with stress during childhood and adolescence. Psychological bulletin, 101 (3), 393.

[8] Etkinson et al., (2001), Hilgard's Psychology, Translated by Dr. Hossein Rafiepour, Volume I, Tehran: Arjmand Publications, Water City, 132.

[9] Powell, W. W. (1987). Hybrid organizational arrangements: new form or transitional development?. California management review, 30 (1), 67-87.

[10] Farzin Rad, B., Asgharnejad Farid, AA., Yekeh Yazdandoost, R., Habibi Asgrabad. M. (2010). Comparison of coping strategies and personality styles in depressed and nondepressed students living in dormitories, International Journal of Behavioral Sciences, 4 (1), 1-17.

[11] froozandeh $N$, dalaram $M$. Effects of cognitive behavioral therapy on the coping strategies of non-medical students of Shahrekord university of medical sciences. J Shahrekord Univ Med Sci. 2003; 5 (3): 26-34.

[12] Ashraf Jahanian, Ali, (2011), The Relationship between Thinking Styles and Stress with Its Strategies, MSc thesis., Islamic Azad University, Central Tehran Branch, Faculty of Psychology and Social Sciences.

[13] Parker, J. D. A., \& Endler, N. S. (1992). Coping with coping assessment: a critical review. European Journal of Psychology, $6,321-344$

[14] Elgar, J., Arlett, C., \& Groves, R. (2003). Stress, coping and behavioral problems among rural and urban adolescents. Journal of Adolescents, 26, 574-585.

[15] Zare, Hossein, Kamali Zarch, Mahmoud and Rezaei Nasab, Fatemeh, (2009), Humorous styles and five personality traits, Iranian Journal of Psychology, (22) 6, 127-119.

[16] Raskin, V. (1985). Semantic Mechanisms of Humor. Dordrecht, the Netherlands: D. Reidel.

[17] Geunsen, M \& Pelsmacker, p. (2002). Role of humor in the persuasion of individuals varying اين need for cognition. Advances اين consumer Research, 29, 50-56.

[18] Martin, R. A., \& Lefcourt, H. M. (2009). Sense of humor as a moderator of the relation between stressors and moods. Journal of Personality and Social Psychology, 45 (6), 13131324.

[19] McGhee, P. E. (2004). The Laughter Remedy: Health, Healing, and the Amuse System. Randolph, NJ: The Laughter Remedy.

[20] Mirsifi Fard, Leila, Fathollah Zadeh, Noushin, Rostami, Mohammadi and Darbani, Ali, (1396), The Effectiveness of Wit Training on Symptoms of Social Phobia, Iranian Journal of Psychology, (53) 14, 85-75. 
[21] Ghorbani, Rababeh, Hosseini, Ali and Elahi, Behnoush, (1396), The Relationship between Wit and Fathers' Coping Styles with Child Adjustment Level, Journal of Child Mental Health, 2 (4): 103-92.

[22] Kamali Eagli, Somayeh, Hassani, Fariba, (2013), The relationship between coping strategies with stress and emotional intelligence with mental health in female students participating in entrance exam classes, Journal of Behavioral Sciences, (1) 7, 56-49.

[23] Pour Sharifi, Hamid, Habibi, Mojtaba, Zarani, Fariba, Ashouri, Ahmad, Hefazi, Mitra, Hajabi, Ahmad, Boallahri, Jaafar (2012), The Role of Depression, Stress, Happiness and Social Support in Identifying Students' Suicidal Thoughts.

[24] Sarmad., Z, Hejazi, Elahe and Abbas Bazargan, (2011), Research Methods in Behavioral Sciences, Tehran: Agha Publications.
[25] Martin, R. A. (1998). approaches to the sense of humor: A historical review. in ruch (ed). The sense of humor $\mathrm{p}, 15-60$.

[26] Martin, R. A., Puhlik-doris, P., Larsen, G., Gray, J., \& Weir, K. (2003). Individual differences in uses of humor and their relation to psychological well-being: Development of the humor styles questionnaire. Journal of Research in Personality, $37,48-75$.

[27] Ben-Zar, H., \& Reshef, Y. (2003). Risk taking and coping Strategies among adolescents. Journal of Adolescence, 26, 255-265.

[28] Seyenezad jeludar, S. Y., Jeludar, Z., AhmadiGhatab, T., \& Shayan, N. (2011). The study of relationship between sense of humor and general health in students. Procedia-Social and Behavioral Sciences, 30, 2057-2060.

[29] Poladi, Ali, and Golestaneh, Seyyed Moussa, (2008), Psychology of Humor, New Generation Publishing, 15-9. 